\title{
DINÁMICA DE UN ORGANISMO NACIONAL DE PATRIMONIO; CONTINUIDADES Y RUPTURAS EN VINCULACIÓN CON PROCESOS HISTÓRICO-SOCIOPOLÍTICOS
}

\author{
MÓNICA B. ROTMAN ${ }^{2}$
}

\begin{abstract}
RESUMEN
En la conformación y gestión de instituciones patrimoniales, el Estado ha ocupado históricamente una posición central. En Argentina (1940) se conforma la Comisión Nacional de Museos, Monumentos y Lugares Históricos (CNMMLH). Su creación instauraba un organismo centralizado, responsable de la operatoria patrimonial y de la formulación de legislación. Se sientan a nivel nacional, prácticas y criterios de selección y validación. Los procesos históricos, políticos y sociales han sido factores co-constitutivos de tales agencias estatales, pautando su relevancia y nivel de visibilización e intervención, fijando categorizaciones, modalidades de gestión y legitimación patrimonial. Analizamos un período de la institución (1946-1952) en el cual se producen modificaciones sustantivas a nivel político-ideológico en el gobierno nacional. Examinamos brevemente la reorganización que el poder político instaura para el ámbito CULTURA, dado que se articula con la ubicación del área PATRIMONIO y analizamos los principales lineamientos de la CNMMLH (continuidades y rupturas) respecto del período anterior.
\end{abstract}

\section{PALABRAS CLAVES \\ Patrimonio; Agencias estatales; Comisión Nacional de Museos; Monumentos y Lugares Históricos; Dinámica institucional (continuidades y rupturas).}

\section{DINÂMICA DE UM ORGANISMO NACIONAL DE PATRIMÔNIO; CONTINUIDADES E RUPTURAS EM RELAÇÃO COM PROCESSOS HISTÓRICO-SÓCIOPOLITICOS}

\begin{abstract}
RESUMO
Na configuração e gestão de instituções patrimonias, o Estado tem ocupado historicamente uma posição central. Na Argentina em 1940 se constitui a Comissão Nacional de Museus, Monumentos e Lugares Históricos (CNMMLH). Sua criação instaurou um organismo centralizado, responsável pela operação patrimonial e pela formulação de legislação. Criam-se, a nível nacional, práticas e critérios de seleçâo e validação. Os processos históricos, políticos e sociais têm sido fatores co-constitutivos dessas agências estatais, que pautam sua relevância e nível de visibilização e intervenção, estabelecem categorizações, formas de gestão e legitimação patrimoniais. Analisamos um período da institução (1946-1952) no qual se produzem modificações substantívas a nível político-ideológico no governo nacional. Examinamos brevemente a reorganização que o poder politico instaura no âmbito da CULTURA, dado que este se articula com a da área do PATRIMÔNIO, e analisamos as principais diretrizes da CNMMLH (continuidades e rupturas) em relação ao periodo anterior.
\end{abstract}

\footnotetext{
1 El presente artículo es una versión modificada de la ponencia presentada en el III Congreso Internacional de Antropología AIBR. Puerto Vallarta, Universidad de Guadalajara, noviembre de 2017.

2 Profesora Titular Regular Universidad de Buenos Aires (UBA); Investigadora Principal del Consejo Nacional de Investigaciones Científica y Técnicas (CONICET); ICA, FFyL, Universidad de Buenos Aires. Contato: mbr30855@gmail.com.
} 


\author{
PALAVRAS CHAVE \\ Patrimônio; Agências Estatais; Comissão Nacional de Museus; Monumentos e Lugares \\ Históricos; Dinâmica institucional (continuidades e rupturas).
}

\title{
DYNAMICS OF A NATIONAL HERITAGE INSTITUTION; CONTINUITY AND IRRUPTION IN RELATION TO HISTORIC AND SOCIO-POLITICAL PROCESSES
}

\begin{abstract}
In the conformation and management of heritage institutions, the State has occupied a central role. In Argentina (1940), the National Council of Monuments, Places and Historic Assets (CNMMLH) was created as a centralized institution responsible of Heritage operation and formulation of legislation. It establish, at national level, practices and criteria of selection and validation. Historic, political and social processes were co-constitutive factors of these kind of state agencies, guiding its relevance and intervention and visibilization level, fixing categories, management modalities and heritage legislation. We analyzed a specific period of CNMMMLH (1946-1952), in which significant modifications occurs in the political and ideological level in the national government. We examine briefly the reorganization that the political power establishes in the CULTURAL field, given the articulation that that has with HERITAGE field. We also analyze the principal guidelines of CNMMLH (continuities and disruptions) of the period proposed.
\end{abstract}

\section{KEYWORDS}

Heritage; State Agencies; National Council of Monuments; Places and Historic Assets; Institutional Dynamics (continuities and disruption)

\section{DYNAMIQUE D'UN ORGANISME DU PATRIMOINE NATIONAL; CONTINUITÉS ET RUPTURES LIÉES AUX PROCESSUS HISTORICO-SOCIO-POLITIQUES}

\section{RÉSUMÉ}

L'État a historiquement occupé une place centrale dans la constitution et dans la gestion d'institutions patrimoniales. En Argentine, est créée en 1940 la Commission Nationale des Musées, Monuments et Lieux Historiques (CNMMLH). Sa mise en place instaure un organisme centralisé, responsable des affaires patrimoniales et de la formulation de textes législatifs. Des pratiques et critères de sélection et de validation sont alors établis au niveau national. Les processus historiques, politiques et sociaux ont joué le rôle de facteurs co-constitutifs de telles agences étatiques, en déterminant sa pertinence et son degré de visibilité et d'intervention, en fixant des catégorisations, des modalités de gestion et de légitimation patrimoniale. Nous analysons une période de l'histoire de l'institution (1946-1952) durant laquelle se sont produites des modifications substantielles au niveau politicoidéologique au sein du gouvernement national. Nous examinons brièvement la réorganisation que le pouvoir politique a mise en œuvre pour les questions de CULTURE, étant donné que cette dernière est alors articulée avec les affaires de PATRIMOINE, et nous analysons les principaux traits de l'institution (ruptures et continuités) en comparaison de la période antérieure.

\section{MOTS CLÉS}

Patrimoine; Organismes d'État; Commission Nationale des Musées; Monuments et Lieux historiques; Dynamique institutionnelle (continuités et ruptures). 


\section{INTRODUCCIÓN}

En el marco de las políticas culturales llevadas a cabo por el Estado, se insertan aquellas patrimoniales, las cuales a nivel nacional son diseñadas y ejecutadas por instituciones cuya creación, fundamentos y criterios se articulan necesariamente con condiciones históricas y políticas específicas.

Hemos analizado en artículos anteriores la actuación de un organismo, rector y central en el tema: la Comisión Nacional de Museos, Monumentos y Lugares Históricos (CNMMLH) ${ }^{3}$ de Argentina y examinado los documentos editados desde su creación. En este trabajo, examinamos su dinámica y las características que la configuran durante el primer gobierno de Juan Domingo Perón ${ }^{4}$ - respecto del lapso anterior -; etapa en la cual comenzaron a implementarse políticas de racionalización y burocratización de las diferentes agencias estatales (CAMMAROTA, 2010, p.65), en articulación con las complejas condiciones socio-políticas del país, que afectarían amplios dominios y sectores de la sociedad, marcando antinomias que perduran hasta la actualidad.

\footnotetext{
${ }^{3}$ En 2015, cambia su denominación a Comisión Nacional de Monumentos, de Lugares y Bienes Históricos (Ley 27.103, sancionada en 2014 y promulgada en 2015).
}

${ }^{4}$ Presentamos una síntesis (básicamente fáctica) simplificada de los hechos históricos acontecidos en ese lapso en nuestro país, atendiendo a los lectores no vernáculos. Recurrimos básicamente al texto de Torre (2001, p. 12-55), sumando datos aclaratorios. J. D. Perón tuvo actuación en distintos hechos políticos: en la Revolución de junio de 1943, en la cual un levantamiento militar derrocó al presidente R. Castillo, siendo designado en su lugar el general P. P. Ramirez. A fines de ese año J.D. Perón fue nombrado director del Departamento Nacional del Trabajo, luego Secretaría de Trabajo y Previsión Social, desde la cual se pautarían relevantes conquistas sociales. En marzo de 1944 asumió el Ejecutivo el Gral. E. J. Farrell, acrecentando su poder J. D. Perón y acumulando los cargos de Vicepresidente, Ministro de Guerra y Secretario de Trabajo; establecería vínculos con sindicalistas, sectores obreros e implementaría beneficios laborales para los trabajadores; la consigna básica de la justicia social quedaba establecida y daría su impronta al peronismo. En 1945, opositores a Perón (básicamente comprendidos entre los sectores medios y altos de la sociedad) cuestionan sus políticas; el gobierno le pide la renuncia y lo confina en la Isla Martin García. Se organiza una huelga general y el 17 de octubre los trabajadores se movilizan a Plaza de Mayo solicitando su libertad. Finalmente en 1946 se realizan elecciones presidenciales. Perón conforma una coalición partidaria y triunfa en los comicios. En 1947, disuelta tal alianza, la agrupación pasa a denominarse Partido Peronista. Combinará en su política la justicia social, el intervencionismo estatal y la sustitución de importaciones. Un fuerte sesgo personalista y medidas conflictivas en distintos ámbitos marcarán este período. Por otra parte, amplios sectores de la población mejorarían su nivel de vida en el plano del trabajo, la seguridad social, la vivienda, la salud, la educación, el turismo social, etc. La bibliografía sobre el peronismo es sumamente amplia, con una producción crítica y compleja. Con perspectivas disímiles se puede consultar entre otros: Ciria (1975; 1983), Romero (2001), Halperin Donghi (2003; 2004), Murmis y Portantiero (2004), Cattaruzza (2009). 
Metodológicamente recurrimos a documentos y fuentes documentales, específicamente los Boletines de la institución, en los cuales se vuelcan las Actas y toda actividad llevada a cabo por el organismo (volúmenes cuya magnitud oscila entre las 400 y 500 páginas).

En 1946, asume democráticamente la presidencia de la Nación Juan Domingo Perón (1ra Presidencia -1946-1951/2-). Y el 30 de julio de ese año Ricardo Levene, primer y único presidente de la CNMMLH hasta esa fecha, presenta la renuncia a su cargo junto con los integrantes del cuerpo directivo ${ }^{5}$, las cuales son aceptadas en julio de ese año. Durante 1947, la Comisión permanecería casi desintegrada. La ley 12.665 no fijaba ningún tipo de quórum, con lo cual la institución podía continuar operando en esas condiciones. Luego de dos Direcciones interinas, en julio de 1948 asumen las nuevas autoridades de la institución.

La renuncia en bloque de los integrantes de la CNMMLH y básicamente de su presidente R. Levene, quien imprimiera su impronta al organismo, se vincula estrechamente con los cambios ideológico-partidarios producidos en el gobierno nacional, ajenos al ideario político con el cual se identificaba el funcionario así como la mayoría de los integrantes de la Comisión.

La antinomia peronismo-antiperonismo, conformada en esos años, marcaría a fuego y a futuro la historia del país, abarcando en esa dinámica dimensiones políticas, ideológicas, sociales, económicas y culturales, persistiendo al presente. No obstante, bajo la sigla partidaria peronista/justicialista, han operado hacia fines del siglo XX gobiernos de corte liberal (política y económicamente), aliados a sectores sociales y conglomerados económicos distantes de su tradición partidaria ${ }^{6}$.

\section{REORGANIZACIÓN DEL ÁREA CULTURA}

Gran parte de la intelectualidad, integrantes del ámbito académico y letrado y sectores medios y altos de la sociedad se opondrían al peronismo. Habiendo una tendencia a minimizarlo en los temas vinculados con la cultura y la educación, lo cierto es que estos tópicos presentaban un grado de complejidad e importancia al cual el gobierno atendió, considerando la conformación de dependencias específicas para su gestión.

La CNMMLH se ubica y articula con un contexto político, ideológico y socio-cultural en el cual el Estado crea agencias definidas para la gestión de la cultura, a la cual pretende dar su

\footnotetext{
${ }^{5}$ La CNMMLH estaba integrada inicialmente por un presidente y diez vocales designados por el Poder Ejecutivo (Decreto № 84.005/41). Sufrirá modificaciones en su composición, durante 1946, 1978 y 1983.

${ }^{6}$ Por caso, Carlos S, Menen (de filiación peronista/justicialista) presidente de la República durante dos períodos consecutivos (1989-1995; 1995-1999).
} 
propia orientación, definiendo sus objetivos y expandiendo su intervención simbólica y material hacia tal espacio ${ }^{7}$.

En Febrero de 1948 el Departamento de Instrucción Pública de la Nación adquiere categoría de Secretaría de Estado con la denominación de Secretaría de Educación de la Nación (Decreto 4026, 14/02/48), a cargo de un funcionario con jerarquía y prerrogativas de Ministro de Estado, siendo designado Oscar Ivanissevich (Decreto $4184-16 / 2 / 48)^{8}$. En 1949 la misma es transformada en Ministerio de Educación, a los fines de centralizar el sistema educativo, fragmentado hasta entonces en procedimientos dispares.

Tal reforma era acompañada simultáneamente de otro cambio relevante, la conformación de la Subsecretaría de Cultura (Decreto 5415/48) como rama integrante de la Secretaria de Educación (jerarquizando al sector). Sus funciones recaían en un Subsecretario de Estado, cargo en el cual fue nombrado Antonio Pedro Castro (Decreto 5902-6/3/48) ${ }^{10}$.

En los Considerandos del Decreto de creación de la Subsecretaría se manifestaba la necesidad de conformar un organismo para el tratamiento de los asuntos relacionados con la cultura; éste centralizaría la dirección administrativa y técnica de las instituciones pertinentes. El plan de Gobierno contemplaba el fomento, la divulgación y la protección de la cultura artística, científica y popular, la producción intelectual, la industria del libro, y el fortalecimiento de sus instituciones representativas (SUBSECRETARIA DE CULTURA DE LA NACION, PLAN DE SU ESTRUCTURACIÓN, 1949, p.10-11).

En el período se observa también un incremento de las partidas presupuestarias para el área. Las mismas se triplicaron en el período, representando una proporción mayor al aumento del gasto público real en su totalidad (FIORUCCI, 2008, p. 4).

Lo cierto es que, pese a las críticas de gran parte de los intelectuales y la instalación de una imagen del peronismo como un gobierno desinteresado y censor de toda iniciativa y práctica en el área cultura, el partido en el poder impulsó una política cultural con ejes programáticos explícitos, así como la creación de instituciones específicas a fin de administrar y

\footnotetext{
${ }^{7}$ No es el objetivo de este texto analizar la política cultural del gobierno peronista, no obstante, el ámbito cultura amerita un breve examen dado su articulación con el área patrimonial.

${ }^{8}$ Fue además Interventor de la Universidad de Buenos Aires entre 1946 y 1948, retomando funciones en el área, en períodos dictatoriales.

${ }^{9}$ El organismo se crea sobre la base de la Comisión Nacional de Cultura, la Dirección General de Cultura y dependencias que actuaban en tal jurisdicción (Decreto 5415/48).

${ }^{10}$ Periodista e historiador autodidacta, director del Palacio San José hasta 1943. En 1945, en Buenos Aires, ocupa la dirección del Museo Histórico Sarmiento. Desde julio de 1947, asume la titularidad de la Comisión Nacional de Cultura; en 1948 dirigirá la Subsecretaría de Cultura (NIÑO AMIEVA, 2007).
} 
gestionar este campo (FIORUCCI, 2008); el Plan de Estructuración de 1949 es un claro ejemplo de ello.

Por otra parte, un hecho político-institucional relevante en 1949 fue la reforma de la Constitución Argentina (sancionada en 1853). La misma fue derogada el 27 de abril de 1956 por el gobierno militar (autodenominado Revolución Libertadora), que asume el poder mediante un golpe de estado en setiembre de 1955.

En el período tratado, las diferencias políticas e ideológicas, los disensos de la intelectualidad, atravesaban el campo cultural e intelectual; el mismo, ya poseía en el país una cierta autonomía y Fiorucci (2008) señala que el peronismo integró a las instituciones estatales a figuras del interior poco reconocidas a nivel nacional o a personajes con escasa trayectoria, lo que contribuyó a tensar dicho campo; ámbito de conflicto, de disputa entre quienes detentaban el poder, el reconocimiento y aquellos que pugnaban por acceder a él y a su legitimación (BOURDIEU, 1993, p. 145-148).

A partir de las reorganizaciones mencionadas, la coordinación y gerenciamiento de la CNMMLH, que cuando se constituyó se ubicaba en el área del Ministerio de Justicia e Instrucción Pública pasaba ahora a depender de la Subsecretaría de Cultura de la Nación. En 1949 se elabora para el área un Plan de Estructuración (retomando el primer Plan Quinquenal, P.Q.) del gobierno11). Se lo plantea como:

"un complejo con unidad temática para cuya preparación fue la norma orientar al pueblo hacia una cultura que le coloque, en ese orden en el puesto preeminente que puede desempeñar en el concierto mundial" (SUBSECRETARIA DE CULTURA DE LA NACION, PLAN DE SU ESTRUCTURACIÓN, 1949, p. 26).

Desde un núcleo central: denominado 1. Despacho General, se proyectan ocho Sectores, (comprendiendo cada uno, diversos tópicos, actividades y sectores de actuación); 2. Política Cultural; 3. Difusión Cultural; 4. Bellas Artes; 5. Investigaciones Culturales; 6. Folkore; 7. Administración de la Cultura; 8. Protección al intelectual; 9. Administrativa, según el Plan de Estructuración de la Subsecretaría de Cultura de la Nación de 1949 (p. 26-27). La CNMMLH se sitúa en el Sector siete Conservación de la Cultura. Sobre el mismo se enuncia

"La conservación de la cultura patria merece museos, archivos y bibliotecas puestas al alcance de nuestros estudiosos y del pueblo en general y la intensificación del conocimiento de esos centros de cultura, con los que deben familiarizarse nuestros ciudadanos ha de ser fundamental deber y preocupación del Estado" (P.Q., página 166, párrafo $2^{\circ}$ ). Así como en la estructura de la Subsecretaría de Cultura tienen su lugar de preferencia la difusión y la investigación cultural, a la conservación de la cultura se le ha destinado un Sector cuya misión específica será atesorar el conjunto de los valores que

\footnotetext{
${ }^{11}$ Desde 1946 se delineó desde la Secretaría Técnica de la Presidencia, el Plan Quinquenal de Gobierno, que establecía la orientación económica del país para el período 1947-1951. Para un examen de la política económica del período consultar Gerchunoff y Llach, 2003, p. 155-242.
} 
constituyen el patrimonio cultural de la Nación. Pero no será algo inerte el fruto de las gestiones administrativas de dicho Sector, ellas habrán de propender a un mayor acercamiento entre los organismos de conservación y el pueblo destinatario y propietario de dichos valores culturales. Tendremos pues, además de Museos, Bibliotecas y Archivos; los Lugares y Monumentos Históricos y Estatuas y Monumentos Públicos, por ser éstos últimos reliquias que perpetúan los mejores recuerdos y los más dignos homenajes que los pueblos elevan a sus fastos del pasado" (SUBSECRETARIA DE CULTURA DE LA NACION, PLAN DE SU ESTRUCTURACIÓN, 1949, p. 41-42).

Este comprende: Archivos, Estatuas y Monumentos Públicos, Bibliotecas, Lugares y Monumentos Históricos y Museos.

Las reflexiones sobre el Sector Cultura son indispensables para comprender el tipo de articulación que se plantea en el período tratado, entre éste y el patrimonio y específicamente con la CNMMLH, conformando la plataforma desde la cual situar la ubicación institucional de ésta última.

\section{LA CNMMLH, CONTINUIDADES Y RUPTURAS}

En esta etapa se produce un quiebre en el perfil de la CNMMLH respecto del período previo.

- Operando en un contexto socio-político distinto de los años anteriores (1940-1945: sucesión de gobiernos conservadores, injerencia militar y golpes de estado), se marcan diferencias en el perfil de sus integrantes. Con una composición heterogénea, provenientes de distintos campos disciplinarios, formación académica diversa, distintas trayectorias y reconocimiento (militares, historiadores, educadores, escritores, periodistas), algunos de ellos con actuación política y desempeño institucional en diversas áreas, difería del cuerpo anterior, conformado mayormente por académicos disciplinariamente procedentes del campo de la Historia, quienes ocupaban en su mayoría posiciones de poder en las arenas políticas e historiográficas (ROTMAN, 2015, p.194).

- La institución pierde la relevancia y jerarquía con que fuera investida durante el período previo.

- Su presidente no ejercería el fuerte liderazgo que caracterizó la actuación de R. Levene; ni ocuparía el lugar relevante que éste tuvo en actividades historiográficas, instituciones culturales y académicas y participación política (ROTMAN, 2015, p.194).

- El Presidente y los miembros de la Comisión mantenían una posición política heterogénea y no tan categórica y manifiesta respecto del gobierno nacional, a diferencia de sus 


\section{Dinámica de un organismo nacional de patrimonio}

antecesores, gran parte de los cuales había sostenido una íntima relación con las máximas jerarquías del Ejecutivo nacional.

- Sobre la disciplina de la Historia, en el Plan de Estructuración de 1949 se la ubica en el Sector cinco, Investigaciones Culturales, al mismo nivel que otras disciplinas. En el texto no obstante, se explicita que es privilegiada dentro del mismo, sumando además su tratamiento una recuperación de la idea de revisión, verificación de los estudios especializados, y preocupación por la alteración de los hechos. Se explicita una concepción certera sobre los usos del pasado como instrumento y argumento político, volcado en narrativas que operaban y daban sustento a la verdadera historia del país. En el examen de los Boletines se observa una recurrencia permanente a la vinculación Historia- Nacionalidad-Argentinidad, lo cual evidencia tal articulación como constitutiva de los referentes patrimoniales y demarca el campo sobre el cual debía operar la CNMMLH. Podemos pensar en cierta semejanza, al menos formal, con las apreciaciones de R. Levene, su explícita y recurrente preeminencia concedida a la Historia, compartida por el gobierno nacional y vinculada con la creciente intervención del estado en las actividades históricas. Señalemos por lo demás, que para el primero era vital la conformación y consolidación de una memoria histórica, la argentinidad, y que consideraba además a la Historia como la máxima disciplina pedagógica de la nacionalidad. La CNMMLH era entendida en esa etapa como ámbito donde dirimir, habilitar y propagar en la sociedad la Historia Argentina y conformar simultáneamente un patrimonio nacional - sin poder no se activa ni se legitima patrimonio (PRATS, 1997).

Por otra parte, durante tal período (1940-1945), la CNMMLH gozaba de jerarquía y marcaba y remarcaba su poder de imposición (ROTMAN, 2015). En el período tratado, se altera la articulación CNMMLH-Patrimonio-Política; declina la apelación al segundo y se debilita la relación con el gobierno nacional; mengua la influencia de la institución y se produce una declinación en el requerimiento e interés por el patrimonio en tanto símbolo de la nacionalidad.

\section{LOS BOLETINES, HUELLAS DE LA CNMMLH}

Los documentos que dan cuenta de las prácticas y concepciones de la CNMMLH se materializan en los Boletines. Aquellos donde constan sus iniciativas y actividades, referidas a los años 1946 y 1947: Boletines Año IX, Número 9 y Año X, Número 10, respectivamente, recién se editan en 1948, siendo los directores interinos responsables de su publicación. En la página de inicio de los Boletines (símil los anteriores), figuran las autoridades: Presidente de la Nación Gral. Juan D. Perón, Secretario de Educación Dr. Oscar Ivanissevich, Subsecretario de Cultura Sr. 
Antonio P. Castro. A continuación, bajo el rótulo Comisión Nacional de Museos y Monumentos Históricos, figuran ya los nuevos integrantes del organismo, su Presidente Dr. Eduardo Acevedo Díaz y los Vocales. A diferencia de períodos anteriores, los últimos son Directores de Museos, en su mayoría dependientes de la institución, más las autoridades del Archivo General de la Nación y de la Biblioteca Nacional, sumando dos militares, uno de ellos Interventor de la Dirección Nacional de Arquitectura.

Las actividades de la Comisión continuaron los mismos lineamientos de años anteriores, manteniendo los Boletines los contenidos, temáticas, y estructura general de su organización. En general, se hallan muy pocas referencias políticas y partidistas explícitas respecto del gobierno nacional, se puede mencionar el Boletín Año IX, No 9 de 1948 (p.29). Los documentos se concentran en las cuestiones tratadas cotidianamente por la CNMMLH, y pese a las transformaciones político-ideológicas planteadas desde el Ejecutivo Nacional, los mismos continúan con una narrativa construida en sus períodos iniciales, validando la historiografía liberal, trabajando en pos de una memoria oficial y legítima. Se mantenía como tópico sobresaliente los homenajes a los Héroes de la patria habilitados por la clase política hegemónica y la exaltación de acciones bélicas relativas al período independentista y a hechos vinculados con la organización nacional (ROTMAN, 2015, p.197-198). Al mismo tiempo se desprestigiaban, y/o invisibilizaban, sujetos y acontecimientos que se concebían ligados implícitamente, desde una dimensión ideológica al gobierno nacional. Se continuaban oponiendo por caso, las orientaciones políticas de J. M. de Rosas y J. J. de Urquiza, siendo los textos sumamente elocuentes. El primero mencionado como el tirano y su gobierno calificando como tiranía ${ }^{12}$ (BOLETín AÑO X, NúMERO 10, 1948, p. 81-83); el segundo elogiado, héroe de la patria, en línea con la historiografía liberal (BOLETíN AÑO X, NÚMERO 10, 1948, p. 247-249; BOLETíN AÑO XII, NÚMERO 12, 1952, p. 73).

Cabe dar cuenta de la corriente historiográfica revisionista, surgida en 1934, que plantearía una versión de la historia diferente de la oficial y hegemónica (HALPERIN DONGHI, $2005)^{13}$ y se erigiría en una contrahistoria, asumiendo una oposición activa en esa lucha entablada por la memoria nacional (QUATTROCCHI WOISSON, 1995). Mencionamos esta

\footnotetext{
${ }^{12}$ Epítetos con los cuales, no casualmente, años después sus oponentes tildarían a J. D. Perón y su gobierno.

13 Movimiento reivindicatorio de los caudillos antiliberales (герresentantes de la barbarie en la historiografía oficial) y particularmente de Juan Manuel de Rosas, construyendo un nuevo panteón de la nación. Se puede consultar Plotkin, 2013, p. 33-35, a respecto de la situación y actuación de la CNMMLH, Rotman, 2011; 2014.
} 


\section{Dinámica de un organismo nacional de patrimonio}

cuestión dado que los integrantes del movimiento revisionista se ubicaban cercanamente a J. D. Perón.

En los Boletines la línea historiográfica no se modificó. No variaron los juicios y valoraciones, ni se plantearon reparaciones. El interrogante apunta a las causas que motivaron este no corrimiento historiográfico-político-ideológico en los documentos de la Comisión, la cual se suponía expresaba y respondía (como lo había hecho anteriormente) al gobierno nacional; pero tampoco se posicionaba como ámbito de oposición o de condición independiente.

Planteamos algunas hipótesis:

1- Es en otros espacios ajenos a la Comisión donde se van conformando representaciones, significaciones e imágenes que actúan como soportes simbólicos, anclajes del gobierno justicialista. Esto implica un viraje en la concepción del gobierno nacional sobre la CNMMLH respecto de su efectividad ideológica en la operatoria sobre la sociedad. La misma está en proceso de cambio y las transformaciones económico-sociales, políticas y culturales, trastocan ciertos órdenes previos en las identidades colectivas y las subjetividades.

2- En relación con lo anterior, al gobierno justicialista no le habría interesado dar batalla en ese frente y fue un tema ajeno a su agenda.

3- El poder Ejecutivo no fue propenso a confrontar con una línea historiográfica que no le suscitaba totales desacuerdos; de ahí que no intrusara la producción la CNMMLH.

4- El gobierno justicialista medía la urgencia de concretar su plan de gobierno y confiaba y estimaba más eficaces otros mecanismos y operatorias que aquellos que podía aportar la CNMMLH.

Por otra parte, hay una discontinuidad en los Boletines (los cuales prosiguen además asumiendo mayormente el carácter de documentos técnicos ${ }^{14}$ ). El del año XIII, Número 13 se publicará recién en junio de 1956 (post golpe de estado) dando cuenta sintéticamente de la actuación de la CNMMLH en el período 1950-1955. Continúa con sus Secciones fijas, informando las actividades cumplidas. El Boletín Año 14, No 14, se editará recién en1958, abarcando desde enero de 1956 hasta diciembre de 1957, con el país ya gobernado por un gobierno de facto.

\section{TÓPICOS INMANENTES A LA CNMMLH}

\footnotetext{
${ }^{14}$ Es significativa la ausencia de referencia al fallecimiento de Eva Duarte, producido el 26 de julio de 1952. 
Ciertos temas han sido considerados fundamentales para la CNMMLH y tratados en sus Boletines desde los comienzos hasta la actualidad; siendo retomados y reformulados acorde a los parámetros de los distintos períodos históricos. Planteamos dos de ellos.

1. La elección y sistematización de los criterios de patrimonialización, así como las pautas no admisibles para tal categorización.

En el período tratado se consideraron como parámetros pertinentes:

- El valor histórico (establecido desde las primeras disposiciones de la CNMMLH).

- La construcción de réplicas de muebles (BOLETín AÑO XI, NúMERO 11, 1949, p. 400 y ss).

- La restauración de edificios y monumentos (BOLETín AÑO XI, NúMERO 11, 1949).

- El valor arquitectónico (BOLETíN AÑO XI, NúMERO11, 1949, p. 517, 519).

No resultaban admisibles:

- La innovación (BOLETín AÑO XI, NúMERO 11, 1949, p. 11)

- La reconstrucción, por carecer de valor histórico. (p.e. del Cabildo Histórico de la Ciudad de Santa Fé (BOLETíN AÑO XI, NúMERO 11, 1949, p. 28).

2. El tema de los Museos. Acorde a su status territorial y jurisdiccional, un grupo de éstos dependieron de la CNMMLH desde su creación hasta la actualidad, manteniendo además una vinculación sumamente articulada en ambos períodos con el tópico educativo. Tales instituciones se re-organizan entre 1947 y 1948 y se nombran nuevas autoridades. Continúa en los Boletines una Sección fija en la cual sus Directores elevaban informes anuales, dando cuenta de sus actividades, volcadas en bloques temáticos. Se forma un personal de censistas, se dictan cursos para contar con personal especializado, como en el Museo Nacional (BOLETín AÑO XI, NÚMERO 11, 1949, p. 43, 225-230, 235, 240), se incorporan Museos provinciales, municipales y de particulares, se establece que las reliquias no deben salir de sus Museos (BOLETín AÑO XI, NÚMERO 11, 1949, p. 36-37), etc. Estas instituciones se manejaban con cierta autonomía en algunas actividades. Asimismo, no fue inusual que tales organismos solicitasen fondos a distintas agencias estatales (BOLETíN AÑO XI, Número 11, 1949, p. 244, 259-260).

Es pertinente recordar que R. Levene consideraba a la Historia como la suprema materia educativa y formativa de la nacionalidad, que tal impronta marcaría a la CNMMLH y que en esta línea las instituciones museísticas serían consideradas ámbitos relevantes para su inculcación en las nuevas generaciones (ROTMAN, 2015) y aquellas administradas por la Comisión desempeñarían una función didáctica central.

Ya en el Boletín Año I, Número 1, se manifestaba 
"Los Museos históricos contienen los valores superiores de la patria y los monumentos y lugares enriquecen la tradición de un pueblo y definen su personalidad moral" (1939, p.10).

En las sucesivas publicaciones se proseguiría destacando el rol de dichas instituciones, así como las funciones asignadas a la historia en sus aspectos pedagógicos, cognitivos, políticos e ideológicos, trazando la articulación entre pasado y presente; en tal sentido, se consideraba que los Museos operaban eficientemente en dicha dirección.

\section{A MODO DE CIERRE}

La CNMMLH se creó en un ambiente político que encontró su basamento en las élites del país, en un clima de época en el cual la nacionalidad continuaba su proceso de conformación. Orientada por expertos, las disposiciones de la Institución constituyeron discursos autorizados (SMITH, 2006) del patrimonio.

Se hacía necesaria la inculcación, la reafirmación de la argentinidad, de la patria como sentimiento y espacio de pertenencia no sólo territorial, sino también simbólico, priorizando su continuidad a las futuras generaciones. Y en esta ardua tarea de consolidar el estado-nación, el patrimonio fue considerado un dispositivo fundamental y la Historia su instrumento principal.

A partir del 46 el proyecto de país que Levene compartía con el gobierno nacional se transforma. La realidad socio-política se ha modificado. Asume el poder un gobierno democrático, con otro modelo socio-económico y adquiere visibilidad un nuevo sujeto social; varía la relación de fuerzas de los sectores laborales y los cambios impactan en una sociedad atravesada por profundas grietas ideológicas.

Un discurso del Presidente de la CNMMLH (Dr. Eduardo Acevedo Díaz), pronunciado en el Acto de inauguración del Museo Histórico del Norte, en Salta (agosto de 1949), es esclarecedor respecto de la situación de la Comisión en este período

“Nuestra institución está aún fuera de su ambiente, porque es de previa formación la conciencia de la cultura.

En este sentido, estamos inmaduros.

La Subsecretaría de Cultura de la Nación pugna por acelerar esta maduración, y pugna también, la Comisión Nacional desde su ángulo solitario.

¿Cuál es entonces, el sentido de la misión de la Comisión Nacional?

Su misión es devolver a los siglos la tibieza humana que tuvieron, y escudar la tradición, en cuanto tiene de factor fundador de patria (BOLETIN AÑO XII, NÚMERO 12, 1952, p. 220221)".

Comprometido con la nacionalidad, en tanto práctica y sentimiento, el justicialismo correrá las bases sobre las cuales se sustentará y valorizará un tipo cualificado de país, con una identidad propia y emergente, una argentinidad replanteada. Es un proyecto de país el que está en 
juego. Sobre éste, interesan los pilares sobre los cuales se sostiene el régimen gubernamental. Es en ellos donde se ubican los cambios y son éstos los que serán puestos en valor. visibilidad y dignificación de sectores trabajadores, beneficios laborales, justicia social, educación, salud, mejoras en el nivel de vida de sujetos colectivos antes postergados. Barbeito y Lo Vuolo (1995) sostienen que durante el gobierno peronista, la construcción de ciudadanía no se produjo a través de la consecución de derechos civiles, sino de derechos laborales.

La Doctrina Peronista, declarada doctrina nacional por ley del Congreso en $1952^{15}$ señalaba tres principios básicos: justicia social, independencia económica y soberanía política (PLOTKIN, 2013, p. 54-55).

En el período tratado, el patrimonio pierde visibilidad como constructor de nacionalidad y conformador de una identidad homogénea y argentina. La CNMMLH continúa su desempeño aunque de manera casi mecánica, con débil registro del presente que está viviendo el país; con un funcionamiento acotado, se autonomiza en cierta manera de la realidad, recortando estrictamente su campo y manteniéndose casi al margen de toda exterioridad y los Boletines parecieran estar inmersos en sus propias y cuasi atemporales circunstancias.

Durante el gobierno peronista la preeminencia simbólica ancla en ciertos símbolos y rituales, actos y conmemoraciones públicas, celebraciones patrióticas y multitudinarias, imágenes, representaciones, construcciones materiales, prácticas que aunarán elementos emocionales, ideas y valores; se conformará un imaginario político-social peronista, contenidos y configuraciones que la CNMMLH difícilmente puede articular bajo la estructura asumida.

Resulta ilustrativo un proyecto del gobierno nacional para erigir obras conmemorativas.

Eva Duarte ${ }^{16}$ deseaba construir el Monumento al Descamisado de la Patria y expresaba:

"Que sea el mayor del mundo. Tiene que culminar con la figura del Descamisado, en el monumento mismo haremos el museo del peronismo, habrá una cripta para que allí descansen los restos de un descamisado auténtico, de aquellos que cayeron en las jornadas de la Revolución. Allí espero descansar también yo cuando muera", fueron las instrucciones de Evita a su escultor favorito, el italiano León Tommasi (citado por JAWTUSCHENKO, 2004) ${ }^{17}$.

En 1952 se sanciona la Ley 14.124/52, con el objetivo de formar una Comisión Nacional del Monumento a Eva Perón, que llevara a cabo tal iniciativa.

\footnotetext{
15 Y precisada como tal, señala Plotkin, en el Segundo Plan Quinquenal (2013, p. 54).

${ }^{16}$ Infatigable trabajadora en pos del bienestar de los trabajadores e impulsora del voto femenino en el país; consorte del presidente.

17 Para un registro detallado del proyecto, ver el interesante artículo periodístico de Ignacio Jawtuschenko, titulado La increible historia del megamausoleo peronista, la octava maravilla, publicado el 10 de octubre de 2004 en Radar, suplemento de Página 12.
} 
La CNMMLH no tuvo ninguna intervención en el proyecto ni en su ejecución. La obra quedó trunca y sus piezas fueron arrasadas por el golpe militar de 1955.

El tema patrimonial, conjuntamente con su institución de referencia, no fue durante el gobierno peronista una prioridad en la agenda estatal y la articulación entre Estado (política) y CNMMLH (patrimonio) fue muy débil o prácticamente nula.

Por lo demás, y respecto de los Boletines, su característica aséptica y formal, tiene su contracara: una vez realizado el proceso de selección que opera respecto de los hechos y de los protagonistas de la historia, quienes han sido los héroes y quienes los villanos de la misma, en los textos no se ahorran epítetos y en este punto cambian su sobriedad y mesura, adquiriendo el carácter de una narrativa heroica, casi épica; emotiva, dramática, memorable, cuyas expresiones no habilitan dudas sobre lo que se desea transmitir; es una forma de avanzar en la construcción de una visión del pasado.

Cabe señalar además, que se trata de un período que no es pródigo en Declaratorias patrimoniales, comparativamente con anteriores etapas históricas y que la CNMMLH no instala su impronta en los referentes legitimados.

En tales años se modifican las formas de expresión de una memoria e identidad que se fragmentan; de una nacionalidad que se construirá a partir de otros referentes, de diferentes símbolos, de la emergencia y visibilidad de otros sujetos sociales. La potencia simbólica que anteriormente revestía el patrimonio, así como el poder de imposición de la CNMMLH sobre tópicos que excedian cuestiones patrimoniales, se verá disminuída en este período y más bien transpuesta y asumida por otros elementos y dispositivos, distintos canales, mecanismos y modalidades de expresión.

Las funciones de legitimación y reproducción del orden existente a las que había contribuido activamente la CNMMLH mediante su tratamiento de la temática patrimonial, se modificarían en un contexto socio-político cambiante, en el cual el gobierno nacional imponía nuevas reglas de juego y sectores de la sociedad redefinían sus identidades, sus derechos, sus prácticas y en definitiva su lugar en el ámbito societario de la nación. Se desarrollan vías de expresión, de legitimación, de imposición simbólica, que devalúan, que implican una pérdida de poder del principal organismo nacional rector de patrimonio: la CNMMLH.

\section{REFERENCIAS:}

BARBEITO, Alberto; LO VUOLO, Rubén. La modernización excluyente. Buenos Aires: UNICEF/CIEPP/LOSADA, 1995. 
BOURDIEU, Pierre. Cosas Dichas. Barcelona: Gedisa, 1993.

CAMMAROTA, Adrian. El Ministerio de Educación durante el Peronismo: Ideología, Centralización, Burocratización y Racionalización Administrativa (1949-1955). Revista Historia de la Educación Latinoamericana, v.15, p. 63-92, 2010.

CATTARUZZA, Alejandro. Historia de la Argentina 1916-1955. Buenos Aires: Siglo XXI, 2009.

CIRIA, Alberto. Partidos y poder en la Argentina moderna (1930-1946). Buenos Aires: Ediciones de La Flor, 1975.

CIRIA, Alberto. Política y cultura popular en la Argentina peronista. Buenos Aires: Ediciones de La Flor, 1983.

FIORUCCI, Flavia. Reflexiones sobre la gestión cultural bajo el Peronismo. Nuevo Mundo. Mundos Nuevos. Debates, 10 de febrero 2008. Disponible en: http://nuevomundo.revues.org/24372 UR: http://journals.openedition.org/nuevomundo/24372; DOI : 10.4000/nuevomundo. Acceso en: junio de 2016.

GERCHUNOFF, Pablo; LLACH, Lucas. El ciclo de la ilusión y el desencanto. Un siglo de políticas económicas argentinas. Buenos Aires: Ariel, 2003.

HALPERIN DONGHI, Tulio. El revisionismo histórico argentino como visión decadentista de la historia nacional. Buenos Aires: Siglo XXI, 2005.

HALPERIN DONGHI, Tulio. La Argentina y la tormenta del mundo. Ideas e ideologías entre 1930 y 1945. Buenos Aires: Siglo XXI, 2003.

La República imposible (1930-1945). Tomo V de la Biblioteca del Pensamiento Argentino, Buenos Aires: Ariel, 2004.

JAWTUSCHENKO, Ignacio. La increible história del megamausoleo peronista, "la octava maravilla". Artículo Periodístico RADAR suplemento del Periódico Página 12, 10 de octubre 2004.

MURMIS, Miguel; PORTANTIERO, Juan Carlos. Estudios sobre los orígenes del Peronismo. Buenos Aires: Siglo XXI, 2004.

PLOTKIN, Mariano. Mañana es San Perón. Buenos Aires: EDUNTREF, 2013.

PRATS, LLorenc. Antropología y Patrimonio. Barcelona: Ariel, 1997.

QUATTROCCHI-WOISSON, Diana. Los males de la memoria. Buenos Aires: Emecé Editores, 1995.

ROMERO, Luis Alberto. Breve historia contemporánea de la Argentina. Buenos Aires: FCE, 2001.

ROTMAN, Mónica. Trama de uma Institucao Estatal vinculada ao Patrimonio Argentino: Contexto Histórico e Regulamentacao. En: FERREIRA, L. ROTMAN, M. MENEZES, L. (Orgs.). Patrimônio cultural no Brasil e Argentina: estudos de caso. São Paulo: Annablume, 2011, p. 51-68. 
Institucionalización del campo patrimonial nacional. Historia, normativa y pautas clasificatorias: un estudio de caso. En: GONZALEZ DE CASTELLS, Alicia; da CUNHA SANTOS, J. (Orgs.). Patrimônio cultural e seus campos. Florianópolis: Editora UFSC, 2014. p. 189-209.

La Comisión Nacional de Museos y de Monumentos y Lugares Históricos: proceso de un ámbito institucional de construcción y gestión de patrimonio y su dimensión política. En: DE CAMPOS, Y. (Org.). Patrimônio Cultural Plural. Belo Horizonte: Arraes Editores, 2015. p.191-208.

NIÑO AMIEVA, Alejandra. Instituciones Culturales, Discurso e Identidad. Adversus, Año IV, n. 8-9, abrilagosto 2007.

SMITH, Laurajane. Uses of Heritage. London: Routledge, 2006.

TORRE, Juan Carlos. Introducción a los años peronistas. En: TORRE, J. C. (Dir.). Nueva Historia de la Argentina, tomo 8, Los años peronistas (1943-1955) Buenos Aires: Sudamericana, 2001.

\section{FUENTES DOCUMENTALES:}

BOLETINES de la COMISIÓN NACIONAL DE MUSEOS Y DE MONUMENTOS Y LUGARES HISTÓRICOS Año I, N. 01. Buenos Aires: Imprenta de la Universidad de Buenos Aires, 1939.

Año IX, N. 09. Buenos Aires: Imprenta Ferrari Hermanos, 1948.

Año X, N. 10. Buenos Aires: Imprenta Ferrari Hermanos, 1948.

Año XI, N. 11. Buenos Aires: Talleres Gráficos Didot, S.R.L. 1949.

Año XII, N. 12. Buenos Aires: s/d. 1952.

Año XIII, N. 13. Buenos Aires: Establecimientos Gráficos E.G.L.H. 1956.

Año XIV, N.14. Buenos Aires: CESA Talleres Gráficos S.R.L. 1958.

PLAN DE SU ESTRUCTURACIÓN. Buenos Aires: Subsecretaría de Cultura, Ministerio de Educación. 1949. Disponible en:

http://repositorio.educacion.gov.ar/dspace/bitstream/handle/123456789/90551/EL000838.pdf?sequence=1 Acceso en junio de 2013.

LEY 27.103, sancionada el 17 de diciembre de 2014 y promulgada en 2015. InfoLEGeg. Ministerio de Justicia y Derechos Humanos, Presidencia de la Nación. Disponible en: http://servicios.infoleg.gob.ar/infolegInternet/anexos/240000-244999/241196/norma.htm. Acceso en mayo de 2011. 
DECRETO N. 84.005, de 1941. Reglamentario de la Ley 12.665, Modificatorio del Reglamento de la Comisión Nacional de Museos y de Monumentos y Lugares Históricos. Buenos Aires: Dirección Nacional del Sistema Argentino de Información Jurídica. Secretaría de Justicia. Disponible en https://cice.vuce.gob.ar/normativa/normativa_infoleg/251270 - Acceso en diciembre de 2017.

DECRETO N. 4026, de 14 de Febrero de 1948. Creación de la Subsecretaría de Educación. PLAN DE SU ESTRUCTURACIÓN. Buenos Aires: Subsecretaría de Cultura, Ministerio de Educación. 1949. p. 7-8. Disponible en http://repositorio.educacion.gov.ar/dspace/bitstream/handle/123456789/90551/EL000838.pdf?sequence=1. Acceso en junio de 2013.

DECRETO N. 4184, de 16 de Febrero de 1948. Designación de S.E. el Sr. Ministro Secretario de Educación. Buenos Aires: Subsecretaría de Cultura, Ministerio de Educación. 1949. p.9. Disponible en http://repositorio.educacion.gov.ar/dspace/bitstream/handle/123456789/90551/EL000838. pdf?sequence=1. Acceso en junio de 2013.

DECRETO N. 5415 de 1948. Creación de la SubSecretaría de Cultura. Buenos Aires: Subsecretaría de Cultura, Ministerio de Educación. 1949. p. 10-12. Disponible en http://repositorio.educacion.gov.ar/dspace/bitstream/handle/123456789/90551/EL000838. pdf?sequence=1. Acceso en junio de 2013.

DECRETO N. 5902, de 6 de marzo de 1948. Designación de S.E el Sr. Subsecretario de Cultura. Buenos Aires: Subsecretaría de Cultura, Ministerio de Educación. 1949. p. 13. Disponible en http://repositorio.educacion.gov.ar/dspace/bitstream/handle/123456789/90551/EL000838. pdf?sequence=1. Acceso en junio de 2013.

Recebido em 30 de julho de 2018. Aprovado em 06 de dezembro de 2018. 